\title{
ACOLHIMENTO PSICOLÓGICO \\ E AFETO EM TEMPOS DE PANDEMIA: PRÁTICAS POLÍTICAS DE AFIRMAÇÃO DA VIIDA
}

\author{
RECEPCIÓN PSICOLÓGICA Y AFECTO EN TIEMPOS DE PANDEMIA: \\ PRÁCTICAS POLÍTICAS DE AFIRMACIÓN DE VIDA
}

PSTCHOLOGICAL CARING AND AFFECTION IN TIMES OF PANDEMIC: LIFE-AFFIRMING POLITICAL PRACTICES

\author{
Laura Cristina de Toledo Quadros ${ }^{1}$, \\ Claudia Carneiro da Cunha ${ }^{1}$ e Anna Paula Uziel ${ }^{1}$
}

${ }^{1}$ Universidade do Estado do Rio de Janeiro (UERJ), Rio de Janeiro/RJ, Brasil

\begin{abstract}
RESUMO: Este artigo tem como proposição discorrer acerca do acolhimento psicológico enquanto uma prática política de afirmação da vida e da saúde no panorama nacional, onde as políticas públicas para tratar a pandemia de Covid-19 tomam rumos distanciados de uma noção mais ampla de cuidado. Inspiradas na vivência de atuar em um dispositivo de acolhimento de uma universidade pública nesse momento de pandemia, nosso objetivo neste texto consiste em discutir os desafios para ultrapassar um modelo clássico de "acolhimento" em psicologia. Fundamentadas na cartografia, percorremos 05 pistas: “a-pandemia-em-nós”, “o acolhimento e seus rastros”, "contato, contágio e a potência dos encontros", "o cuidado como revolução numa experiência viva de afirmação da vida" e "amparo e afeto numa prática engajada”. Tais pistas problematizam a prática do acolhimento psicológico partindo da reconfiguração das fronteiras relacionais em situações extremas, no caso, a pandemia, bem como das afetações que esse intervir produz nesse campo de atuação.
\end{abstract}

PALAVRAS-CHAVE: Acolhimento; Práticas em psicologia; Pandemia; Covid-19; Políticas de afirmação da vida.

RESUMEN: Este artículo propone hablar de la recepción psicológica como práctica política de afirmación de la vida y la salud en el panorama nacional, donde las políticas públicas para hacer frente a la pandemia Covid-19 se alejan de una noción más amplia de cuidado. Inspirándonos en la experiencia de trabajar en un centro de acogida psicológica de una universidad pública en este momento pandémico, nuestro objetivo en este texto es discutir los desafíos para superar un modelo clásico de "recepción "en psicología. A partir de la cartografía, cubrimos 5 pistas: "la-pandemia-em-nosotros", "la acogida y sus huellas", "contacto, contagio y el poder de los encuentros ", "el cuidado como revolución en una experiencia viva de afirmación de vida” y "apoyo y afecto en una práctica comprometida”. Tales pistas problematizan la práctica de la recepción psicológica a partir de la reconfiguración de los límites relacionales en situaciones extremas, en este caso la pandemia, así como de los afectos que esta intervención produce en este campo de acción.

PALABRAS CLAVE: recepción; prácticas en psicología; pandemia; Covid-19; políticas de afirmación de la vida.

ABSTRACT: This article proposes to discuss psychological care as a political practice of affirming life and health in the national scenery, in which public policies to address the Covid-19 pandemic have taken a step away from a broader notion of care. Inspired by the experience of working in a public university psychological care facility during this pandemic, our aim with this text is to discuss the challenges to overcome a classic model of "caring" in psychology. Based on cartography, we follow 5 clues: "the-pandemic-in-us", "the psychological care and its tracks", "contact, contagion and the power of encounters", "caring as a revolution in a living experience of affirmation of life" and "support and affection in a committed practice". Such clues problematize the practice of psychological care starting from the reconfiguration of relational boundaries in extreme situations, in this case, the pandemic, as well as from the affections that this intervention produces in psychology.

KEYWORDS: caring; psychology practices; pandemic; Covid-19; life-affirming policies. 


\section{Primeiros contornos: recolhendo pistas}

Este artigo tem como proposição discorrer acerca do acolhimento psicológico enquanto uma prática política de afirmação da vida e da saúde no panorama nacional, onde as políticas públicas para tratar a pandemia de Covid-19 tomam rumos distanciados de uma noção mais ampla de cuidado. Nem sempre tais noções consideram alguns norteadores técnicos mínimos para pensar os impactos da epidemia nas subjetividades, relações interpessoais e domésticas (Ministério da Saúde, 2020a, 2020c, 2020g), nas dimensões ritualísticas (Ministério da Saúde, 2020e), de gestão (Ministério da Saúde, 2020f) e nas práticas da psicologia (Ministério da Saúde, 2020b), hoje majoritariamente exercidas no formato online (Ministério da Saúde, 2020d).

Inspiradas na vivência de atuar em um dispositivo de acolhimento de uma universidade pública nesse momento de pandemia, nosso objetivo neste texto consiste em discutir os desafios para ultrapassar um modelo clássico de "acolhimento" em psicologia.

Buscamos estabelecer articulações entre os campos da clínica e da psicologia social, afastando-nos de uma perspectiva que os polarize ou os distancie nas suas possibilidades de diálogo e construção conjunta. Intencionamos também problematizar as chaves interpretativas vinculadas à interioridade e à individualidade para tratar a questão do sofrimento individual e coletivo em situações extremas, no caso, os impactos da pandemia na vida das pessoas, especialmente, no Brasil, com suas marcas excludentes advindas das gravíssimas desigualdades sociais.

Seguimos os rastros de algumas autoras, principalmente de Donna Haraway (1995, 2008), Vinciane Despret (2004), Isabelle Stengers (1989) e Annemarie Mol (2007, 2008, 2018), que abordam a dimensão da construção do conhecimento a partir de uma abordagem não generalista, para situar o lugar de onde falamos. Somos psicólogas, professoras universitárias, pesquisadoras de uma universidade pública do Rio de Janeiro que já vem há anos resistindo às tentativas de sucateamento da universidade pública, no quadro muito bem descrito por Boaventura Souza Santos (2020), resumido nos conceitos de capitalismo universitário e ultradireita ideológica, que chega ao Brasil cada vez com mais força.

A metáfora da guerra utilizada, tantas vezes, por instâncias nacionais e internacionais como referência ao enfrentamento da Covid-19, já nos é familiar em nossas experiências cotidianas na universidade pública, em face ao desmonte que vivenciamos com o desinvestimento na educação pública, gratuita e de qualidade. No entanto, estamos muito atentas aos aspectos simbólicos produzidos com a ideia de "guerra".

A linguagem militar já permeou diversos universos na história do Ocidente, "guerra ao cancro", "guerra à pobreza", "guerra às drogas", entre outras. "Guerra” não é uma inocente e casual metáfora, uma vez que as representações enquadram a direção da pesquisa e também a abordagem clínica, no caso de doenças. Opera como um instrumento cognitivo que torna possível mapear e direcionar a ação. E essas representações funcionam como um mediador entre o social e o biológico, cujo impacto se dá nos dois sentidos, acabando por influenciar o decurso das epidemias (Bastos, 2002).

Nesse sentido, nosso intuito aqui, partindo das pistas produzidas por uma iniciativa de acolhimento psicológico online oferecida a docentes, funcionários técnico-administrativos e alunos/as da Universidade, realizada desde o início da pandemia de Covid-19, não é simplesmente de discutir definições ou metodologias de acolhimento, mas sim trançar fios, 
permitindo fazer emergir uma trama que não reduza o acolhimento à escuta das aflições e ansiedades individuais que gritam nesse momento. Essa convocação nos leva a reconhecê-lo enquanto uma prática de cuidado, constituindo-se, assim, na afirmação da vida e da saúde num contex to em que o outro é posto como fonte de ameaça, e a morte está sendo trivializada.

Se consideramos que acolher pode se desdobrar na busca pelo possível potencial criativo de cada um, bem como na ideia de que o sofrimento diante do inusitado desarruma a norma e provoca a criação de uma normatividade (Canguilhem, 1904/1995) que corresponda aos desafios do meio, podemos considerá-lo como um pequeno gesto transgressor diante de uma necropolítica (Mbembe, 2018), que nega o perigo como real e a proteção como fonte de afirmação da vida.

Pensando a psicologia nessa circunstância, faz-se pertinente discutir o efeito ético e político que o acolhimento pode deflagrar, se o situarmos nessa fronteira de uma prática clínica afetada por um campo de acontecimentos vivos, coletivos, múltiplos. Inspiradas na noção de ontologias políticas indicada por John Law e Annemarie Mol (1995) e reafirmada pela própria Mol (2018), refletimos acerca de que mundo queremos produzir com nossas práticas, que versões são colocadas em cena e que psicologia estamos fazendo emergir nesse nebuloso cenário. Os autores supracitados trazem esse alerta ao afirmarem que ontologia não precede práticas de conhecimento, mas é instaurada por elas. Assim, a realidade segue múltipla e o que realizamos é uma de suas versões.

$\mathrm{O}$ acolhimento pode ser visto como um momento de parada, um debruçar-se sobre algum ponto, algum traço, alguma questão, uma pausa para nomear o caos, que é originário do pensamento (Deleuze \& Guattari, 1992). O caos que é crise, mas é potência de vida.

Apoiadas no método cartográfico, desenvolvemos este trabalho seguindo pistas que nos ajudaram a mapear essa noção do acolher como um ato político de resistência e afirmação da vida. Estabelecer pistas permite tornar coletiva a experiência do/a cartógrafo/a (Kastrup, 2007), que se constrói na tecitura de processos singulares, já que através delas é possível trabalhar descrições e promover discussões sobre os processos de construção.

Segundo Eduardo Passos, Virgínia Kastrup e Liliana Escóssia (2009): “As pistas que guiam o cartógrafo são como referências que concorrem para a manutenção de uma atitude de abertura ao que vai se produzindo e de calibragem do caminhar no próprio percurso da pesquisa - o hódos-meta [grifo dos autores] da pesquisa.” (p. 13). Apoiamonos também nessa reversão proposta pela cartografia, na qual não aplicamos um método, mas experimentamos um caminho, uma construção que vai acontecendo tanto na prática quanto na escrita, nos permitindo pensar, experimentar e intervir de modo processual e descentralizado.

Com essa inspiração, apostamos numa prática clínica entrecruzada com a psicologia social, abrangendo o momento, as interferências de uma realidade viva e não individualizada, onde acompanhar processos implica estar atento aos acontecimentos que atravessam nosso viver, para além de uma interioridade.

Partindo da proposição de que "cartografar é acompanhar processos” (Pozzana \& Kastrup, 2009), não iremos objetificar o acolhimento, ao contrário, escolhemos (des)dobrá-lo e pensá-lo em movimento, considerando, inclusive, os desafios que ele nos traz. Tomá-lo enquanto um dispositivo de afetos e afetações em tempos nos quais nossa aproximação está mediada por aparelhos eletrônicos é, sobretudo, ressignificá-lo enquanto intervenção. 
Portanto, a partir de uma experiência viva de construir dispositivos de acolhimento na universidade em tempo real, duas semanas após a decretação do confinamento em nossa cidade pelo governo do Estado, iremos aqui destacar as pistas que nos levam às reflexões contidas nesse texto. Ressaltamos que essas pistas são abertas, como a própria inspiração metodológica nos propõe, e emergiram dessa experiência atravessada em nós.

Apontamos 5 pistas: a pista 1, “a- pandemia-em nós”, emerge de nossa afetação imediata; a pista 2, "o acolhimento e seus rastros", contextualiza o acolhimento possível, deslocando-o de um olhar tradicional e localizando-o nessa imbricação entre o campo da clínica e da psicologia social, uma vez que, nesse momento pandêmico, esses campos se entrecruzam.

A pista 3, "contato, contágio e a potência dos encontros", problematiza esse paradoxo perto-longe como forma de cuidado, pista essa que emerge desse momento onde o acolhimento remoto passa a ser a base do encontro. A pista 4, "o cuidado como revolução numa experiência viva de afirmação da vida”, a partir do que estamos vivendo em nossa universidade, destaca o caráter revolucionário que o cuidado pode ter nesse momento onde privilegiamos uma construção coletiva e criativa em nossas práticas.

Finalmente, a pista 5, "amparo e afeto numa prática engajada", emerge de nossos corpos mulheres-docentes-psicólogas-pesquisadoras que estão percorrendo esse caminho de pensar-fazer psicologia no Brasil nesse desafiante momento de pandemia.

\section{Pista 1: a-pandemia-em-nós}

Certamente, o cenário desenhado pela pandemia de Covid-19 tem alcances inimagináveis e imprevisíveis, trazendo contornos mais dramáticos para além de nossas "batalhas diárias". Porém, resistir, produzir conhecimento a partir da escassez de recursos, buscar soluções criativas e adaptações frequentes, são movimentos comuns em nossas práticas que se multiplicam em situação de crise que, como dizem Gilles Deleuze e Félix Guattari (1996), é um movimento desestabilizador. Além disso, somos mulheres, afetadas por outras jornadas e convocações de cuidado que atravessam nossas vidas de pesquisadoras.

E o que este lugar de mulheres pesquisadoras, atravessadas pelo devir-cuidaracolher, nos incita a pensar? Ao tratar do conceito de análise de implicação, Cecília Coimbra e Maria Lívia do Nascimento (2008) remontam à ideia de René Lourau de que se trata de um "escândalo da análise institucional", exatamente por colocar em questão a supremacia intocável dos especialistas. Em tempos de incertezas, essa pode ser peça chave para duvidarmos de nossas verdades e apostarmos em outras produções de conhecimento que considerem o valor da experiência (Bondía, 2002).

Ampliando os constructos de transferência e contratransferência da Psicanálise, o conceito de análise de implicação rompe de forma radical e intensa com a ideia de neutralidade. É preciso pôr em análise, constantemente, o lugar que ocupamos, o que os encontros despertam em nós, as formas como transbordamos o que nos atravessa, bem como os afetos que nos mobilizam e nos conduzem.

É a partir desse entendimento que os afetos jogam um papel fundamental na produção do conhecimento. Para Jeanne Favret-Saada (2005), o fato de aceitar ocupar esse lugar e ser afetada abre uma comunicação sempre involuntária e desprovida de intencionalidade, e que pode ser verbal ou não. A dimensão da afetação na pesquisa resgata o lugar de uma 
"sensibilidade", que não se confunde com a ideia de "se colocar no lugar do outro". O que está em jogo é ser tomado pelo desconhecido, ser dominado e experienciar a revisão da própria posição de observadora e pesquisadora.

Não perdemos de vista também como norteadores de uma análise crítica os estudos sociais da ciência (Bastos, 2002) que nos alertam sobre as metáforas, representações e sentidos sociais postos em marcha na construção do conhecimento científico, em especial, no campo das ciências naturais, visto de um modo geral como neutro e desinteressado.

É então com estas ferramentas que nos colocamos em cena.

\section{Pista 2: o acolhimento e seus rastros}

A lógica bélica na compreensão da pandemia de Covid-19 e na direcionalidade de suas respostas, médicas, sociais e políticas, é uma dimensão que precisa ser olhada a partir dessa perspectiva, afinal, quem é o inimigo a se combater? Tratar a medicina como guerra, as doenças e seus agentes como inimigos, e a prática clínica como uma sucessão de batalhas, é ratificar um conjunto de metáforas bem adaptadas ao ethos pragmático da medicina (Bastos, 2002). Mas que outros olhares a psicologia pode oferecer para se lidar com as relações de alteridade marcadas pelas ideias de "risco", "perigo" e "combate"? Apostamos aqui na chave analítica e prática do acolhimento.

A noção de acolhimento não é uma novidade nas nossas práticas. Especialmente, a partir de 2004, o Ministério da Saúde reconhece a prática do acolhimento como estratégia de recepção no SUS (Sistema Único de Saúde), em busca de um atendimento mais humanizado ao usuário. Isso gerou, inclusive, uma publicação específica do Ministério da Saúde, "Acolhimento nas práticas de produção de saúde" (Ministério da Saúde, 2010), onde o acolhimento é compreendido como uma ferramenta de intervenção, uma "tecnologia do encontro", onde a escuta e o vínculo constituem um processo de promoção de saúde nos serviços públicos.

No entanto, na perspectiva de Angela Speroni e Rachel Menezes (2014), em um texto sobre acolhimento em unidades básicas de saúde, apesar de estar posta "a concepção do Acolhimento como projeto de (re)humanização no âmbito do sistema público de saúde conjuga um posicionamento ético-político inovador" (p. 381 ), uma vez que substitui a lógica dos procedimentos por processos que consideram autonomia e solidariedade, o acolhimento acaba sendo palco para tensões entre a universalidade do sistema e as desigualdades sociais que gritam no país. O desafio ainda se mantém.

Segundo Cátula Pelisoli, Airi Sacco, Elen Barbosa, Cristiane Pereira e Alessandra Cecconello (2014), apesar da proposição de acolher ser apontada como um encontro humanizado, "A escuta realizada no acolhimento continua sendo essencialmente clínica, inspirada no modelo biológico-médico-hegemônico, muito pontual, focada na queixa." (p. 228). Os autores ressaltam, ainda, que habilidades técnicas são priorizadas em detrimento de uma abordagem mais personalizada, relacional e acolhedora. Portanto, acolher não é de fato uma ação simplificada como pode parecer e, mais do que isso, exige disponibilidade e preparo. Dessa forma, ainda há um afastamento entre o que propõe a teoria e o que acontece na prática, conforme apontam Laura Brehmer e Marta Verdi (2010).

Reconhecido como uma tecnologia leve (Merhy \& Franco, 2003) e de resultados importantes no campo da atenção básica, não é raro que o acolhimento seja visto com 
reservas, ou como uma ação menos fundamental, sem grandes impactos. Algo amenizador ou até mesmo paliativo, sem efeitos mais efetivos. E como compreender ou resgatar esse processo de acolher para além dessa rotina dos equipamentos de saúde? E quando, numa situação inusitada como a que vivemos nessa pandemia, nossos instrumentos de intervenção tornam-se restritos, limitados à escuta e à visão através da tela, sem o encontro presencial?

Resgatar o acolhimento em sua proposição essencial é uma aposta ético-política, nos levando, inclusive, a reconhecer lacunas importantes em nossa formação que, historicamente, prioriza as grandes intervenções fundadas no diagnóstico, no poder do psicoterapeuta de atuar de modo hierárquico reproduzindo o modelo médico clássico. Ou ainda, a valorização de processos extensos avaliados por sua duração no tempo.

E qual foi nosso desafio ao nos encontrarmos diante dessa pandemia que desarrumou nossas vidas e nossas práticas? Fomos convocadas a agir coletivamente colaborando para a criação de uma estratégia que pudesse ser oferecida, tendo clareza que a universidade é formada por um universo heterogêneo com cerca de 40.000 pessoas, englobando discentes de todas as graduações e pós-graduações, técnicos administrativos e docentes de uma universidade pública.

Foram mobilizados em torno de 50 psicólogas e psicólogos voluntários, todos ligados, de alguma forma, à instituição. Uma organização peculiar foi instaurada para que os acolhimentos pudessem acontecer, e o novo se impôs a nós. Porém, nosso devir-mulher-cuidadora-pesquisadora se entrecruza com as durezas das concepções de uma tal condição feminina arraigada em nós, na nossa universidade, em nossos discentes, nossos colegas, afetadas pelos acontecimentos, o que nos lançava em novos desafios.

Fundadas na experiência de estar nesse projeto de acolhimento não presencial em tempos de pandemia, o ato de acolher - às vezes, só através da escuta, ou da escuta e da visão na tela, ou mesmo pela escrita através de e-mails ou aplicativos - percebemos a necessidade de repensar o dispositivo e recriar a forma. E, ao recriar a forma, outro questionamento se interpõe: e se o acolhimento for o próprio contato, o olhar de que tanto se precisa, um instante de atenção, uma palavra genuína não explicativa, um efêmero intenso? E se for um despertar, uma luz sobre a própria vida, um lembrar-se de si junto com o outro?

No olho a olho físico ou mediado pela tela, ainda que se guarde todas as diferenças que não são poucas, a escuta do/a outro/a demanda uma atenção intensa, e deve ser perseguida pelo/a cartógrafo/a. Virgínia Kastrup (2007) destaca dois pontos fundamentais sobre a atenção: não reduzir a função da atenção a uma simples seleção de informações, mas uma busca dos processos em curso. "A detecção e apreensão de material, em princípio desconexo e fragmentado, de cenas e discursos, requer uma concentração sem focalização" (p. 15), ou ainda, uma atenção à espreita.

O outro ponto que a autora levanta é que a atenção pode ser ou não flutuante, dispersa, focada, voluntária ou não, e todas essas combinações são possíveis. No momento intenso do acolhimento, é desta atenção que estamos falando, que vem sendo construída a partir das ferramentas que reinventamos do saber psi. Como a própria Virgínia Kastrup (2007) mais uma vez nos aponta: "A atenção se desdobra na qualidade do encontro, de acolhimento. As experiências vão então ocorrendo muitas vezes fragmentadas e sem sentido imediato.” (p. 18). Isso transcende a técnica e requer disponibilidade.

Resgatando a proposição cartográfica, estar atento, presente, disponível e aberto é uma atitude primordial. Porém, ela não acontece sem tensões e sem invenções, no rastro 
do que nos propõe o método cartográfico. Uma vez que não nos interessa o domínio desse campo, e muito menos acolher para forjar qualquer modo de submissão, a atenção nos convoca à criação, a inventar formas que não excluam os acontecimentos e nos permitam as surpresas dos encontros. Sem roteiros prévios, sem instruções engessadoras, convocando a clínica à vida.

Estamos vivendo esse processo coletivamente, e nossa prática de acolher nos ajuda a ressignificar nossos modos de intervir como psicólogas.

\section{Pista 3: contato, contágio e a potência dos encontros}

Considera-se que com o medo de contágio pela doença, junto com o distanciamento e o isolamento físico como formas de controle da pandemia, seja vivenciada uma carga elevada de experiências e emoções perturbadoras, suscitando a necessidade de cuidados psicológicos constantes desde o período inicial do problema (Ministério da Saúde, 2020e).

Um dos aspectos que nos chamou a atenção e nos provocou a realizar esse trabalho foi a quantidade de pesquisas - a maioria quantitativas - que rapidamente afirmaram o aumento de casos de transtorno de ansiedade, depressão, pânico e até transtorno de estresse pós-traumático (embora a pandemia ainda esteja em curso). Mas o que esperar desse momento? O que pensar de uma situação onde, de um dia para outro, somos ameaçadas por um vírus invisível, altamente propagável, sem evidências de tratamento eficaz, que nos jogando na, sempre existente, condição de afetáveis uns pelos outros na dimensão inexorável da contagiosidade da vida, altera drasticamente a rotina de milhões de pessoas, tendo o isolamento físico como a maior recomendação da ciência e garantia de cuidado com o outro e com o coletivo?

O que aguardar em termos das políticas de cuidado no Brasil, onde autoridades federais, estaduais e municipais não alinham seus discursos em prol da saúde da população? O que contar como efeito social e simbólico quando discursos, claramente negacionistas, são confrontados com o aumento de mortes diárias de pessoas em diversas faixas etárias por Covid-19?

Resgatando a célebre indagação de Georges Canguilhem (1904/1995), "Existem ciências do normal e do patológico?"- há de se ter cuidado com o que estamos produzindo a partir da afirmação do adoecimento em um contexto onde tal reação pode ser exatamente uma expressão de saúde. Portanto, o acolhimento não pode ser apartado desse campo de forças e muito menos encolhido ao papel de aplacar a ansiedade ou outros "transtornos mentais".

$\mathrm{O}$ isolamento físico nos coloca questões singulares sobre acolhimento e afeto, nos obriga a pensar a distância como cuidado, e a tecnologia nos oferece a proximidade através das telas. Diferente das cartas e dos telefones, os recursos midiáticos hoje permitem o olhar, o acesso a uma gama de expressões corporais, mas não a experiência da totalidade dos sentidos que a relação face a face nos traz. Uma tela que promete o todo e mostra partes, que comporta outros fundos, que joga com sons e cantos escondidos na presença imediata e mediada do encontro.

Entendemos que outras corporeidades são forjadas nesse processo, nessa apresentação de si através das telas. Mas essa circunstância excepcional que recria o setting terapêutico e o campo de interação corporal terapeuta-cliente, a partir de um contato mediado pela tecnologia, pode criar corpos híbridos potentes, corporeidades que unem a carne 
e o prolongamento tecnológico: “[a] máquina-objeto se acopla e passa a formar o próprio sujeito" (Albuquerque, 2017, p. 4).

Assim, contato e contágio, proximidade e distância, afetos e acolhimento, formam um conjunto vibrante, paradoxal, onde perto e longe perdem o antagonismo e se transformam em possibilidades. Perto e longe deixam de se referir à distância física e complexificam a trama subjetiva que aproxima ou afasta as pessoas no ato do cuidado.

Estar longe passa quase a uma condição para estar perto, quando a interação face a face não é possível. É a aposta em uma afetação mútua, engajada em fazer valer o potencial transformador da palavra, da melodia da fala, do gesto cúmplice, do silêncio suportado, que torna possível o ato de tratar e acolher "à distância". E é, sobretudo, nesse momento, um ato de cuidado. Sabemos que em outras circunstâncias, como nos casos de violência doméstica, especialmente, dirigida a mulheres, distanciamento é uma medida fundamental de cuidado, uma recomendação essencial para o caminho do acolher e do tratar. O novo neste momento atual é a radicalidade dessa medida, ou seja, ela se faz necessária a qualquer ação de cuidado em nosso campo de atuação.

Apostamos, portanto, nos rumos profícuos que essas mudanças podem engendrar na prática psicológica, enquanto potência de vida e de produção de novos conhecimentos, sem perder de vista as experiências já conhecidas de ser, pensar, agir e sentir que balizam a condição humana, hoje radicalmente revista.

Logo, essa é uma discussão que promove tanto possibilidades inventivas quanto deslocamentos necessários para pensarmos uma prática onde as afetações tornem-se também um recurso (Favret-Saada, 2005), visto que não estamos simplesmente discorrendo acerca da pandemia e seus efeitos, mas estamos convivendo e aprendendo com ela novos modos de intervir que podem fazer a diferença nesse enfrentamento. Apostamos em um fazer com o outro e não sobre ele (Quadros \& Moraes, 2016), sem invisibilizar percalços, compreendendo a ação de acolher como ação de resistência e política de afirmação da vida diante dos desafios atuais.

Acolher neste momento torna-se, então, um processo circular e espiralado pela abertura ao novo, visto que a experiência compartilhada permeia de forma concreta nossos esforços e nossa existência frente à pandemia. Atuamos na fronteira onde o contato alcança novas dimensões sensoriais mediadas pelos dispositivos eletrônicos, o contágio se faz pelas trocas de ideias e emoções e o encontro se transforma em potência. Uma potência afirmativa que ratifica a noção de acolher como permanecer, estar presente, testemunhar, ficar, sustentar o momento e, portanto, produzir vida diante da possibilidade da perda e da morte, sem negá-las como possibilidade.

\section{Pista 4: o cuidado como revolução numa experiência viva de afirma- ção da vida}

Como já apontado anteriormente, a ideia e a prática de acolhimento não são novas no campo da psicologia, tampouco no campo da saúde mental a partir das reformas sanitária e psiquiátrica. Configura uma tecnologia de cuidado que tem como objetivo, entre outros, o alívio mais imediato de situações de sofrimento, o reconhecimento de problemas principais e de recursos pessoais acionáveis em determinado contexto e momento específico. 
Em alguns casos, o acolhimento é percebido a partir de uma lógica hierarquizante, como uma ação de menor status dentro do rol de possibilidades de atuação profissional no campo da psicologia e da saúde.

As situações de emergência, como a que estamos vivendo com a pandemia de Covid-19, parecem recolocar os termos dessa equação em relação ao dispositivo de acolhimento psicológico, alçando-o a um lugar de maior importância e valor, inclusive institucional. A necessidade de ação imediata, a exigência de uma velocidade na organização de estruturas institucionais e de recursos humanos, nunca antes pensados para o atendimento às demandas de sofrimento psíquico, são alguns dos fatores que contribuem para a reconfiguração do acolhimento. Além disso, a reinvenção dos modos de pensar e praticar o acolhimento, de criar espaços de supervisão que também considerem o sofrimento de quem acolhe, de formas de registro diário de uma ação em constante fluxo e movimento, são desafios e possibilidades que se colocam na (re)construção desse dispositivo de cuidado.

Sendo a Psicologia uma profissão tão marcada por práticas individualizantes, a situação de exceção parece ter convocado a categoria à dimensão política e coletiva das produções de subjetividade. A evocação de uma preocupação com a comunidade mais ampla, o desejo de fazer parte da luta contra a pandemia, as ações equivocadas do governo são inspirações talvez inéditas que provocam ocupação de novos lugares que talvez tragam enlevo, mesmo com o desconforto inicial da urgência da criação de uma resposta "rápida" e "eficaz" para o sofrimento coletivo.

Do ponto de vista de quem busca, o que também instiga a construção deste dispositivo, o acolhimento parece ser mais uma possibilidade de contato, neste mundo momentaneamente escasso de abraços e olhares furtivos, do acaso, que podem acontecer a qualquer momento, nos diferentes lugares pelos quais circulamos no corriqueiro dia a dia. Uma busca dirigida por uma atenção de alguém desconhecido, de ser cuidado/a fora da sua esfera, o que certamente também produzirá saltos e mergulhos inéditos na experiência pessoal de cada um, de quem acolhe e de quem é acolhido.

O cuidado aqui, diferente da diretriz que norteia a assistência médico-curativa, centrada na doença e nas práticas que as legitimam, é pensado como aquilo que se produz na arte do encontro com o outro. Um outro que tem saberes sobre sua experiência de sofrimento e dor, e que pode vocalizá-la ao seu modo, com seus próprios recursos. É neste sentido que falar de cuidado é considerar os "projetos de felicidade" envolvidos no ato de tratar (Ayres, 2004).

Segundo José Ayres (2004, p. 19), ao tomarmos os "projetos de felicidade" como horizonte normativo, teremos que usar a "sabedoria prática", ou seja, precisaremos fundir horizontes entre nossos saberes técnicos e os saberes que as pessoas de quem cuidamos acumularam sobre si mesmas, com a abertura necessária para que, da troca e do diálogo entre esses saberes, surjam boas escolhas sobre como agir nas diversas situações de cuidado. Esse é um processo que emerge de um espaço relacional e não se concentra nem no indivíduo, nem na hierarquia.

Nesse sentido, Mol (2008) nos propõe uma "Lógica do cuidado" que acontece a partir de práticas que se afastam de uma proposição mercadológica, neoliberal, que não levam em conta as múltiplas forças que compõem o cuidar. Para a autora, "O cuidado não é uma negociação na qual algo é trocado (um produto por um preço); é uma interação na qual a ação vai e vem (em um processo contínuo).” (Mol, 2008, p. 21, tradução nossa). 
Tal afirmação, a nosso ver, ratifica o caráter político dessa parceria acolher-cuidar, no caso aqui discutido, uma política de afirmação da vida. A vida em seus muitos possíveis, sem o imperativo da felicidade, sem assepsia de mal-estares, sem a negação dos acontecimentos. Diante de uma pandemia, onde vida e morte andam literalmente lado a lado, caminhamos no fio da navalha e, nesse cenário de ameaças e incertezas, o cuidado torna-se um ato revolucionário que habita o nosso cotidiano.

Revolucionar assume aqui um de seus sentidos ampliados: revolver, movimentar, revirar. Assim, esse movimento vai além do informar, do legislar e do prescrever, ações que emergiram tão rapidamente nesses tempos pandêmicos, nos deslocando, nos convocando a fazer diferente. Como a própria $\mathrm{Mol}$ (2008, 2018) nos alerta, o outro a quem dirigimos o cuidado - seja o paciente, seja o acolhido - é ativo, interfere e participa dessa "revolução", engrossando as fileiras de nossas estratégias de viver a cada dia. E são essas revoluções diárias que podem fortalecer nossa condição de resistir para afirmar a vida.

Não podemos deixar de considerar que essa dimensão mobilizadora e transformadora do acolhimento é uma escolha e direção ética e política, no sentido de valorizar a potência do encontro como ato de criação de outros e novos devires. No entanto, ele também pode ser pensado e praticado como um ato despontencializador do encontro e da diferença, distanciando-se do que discutimos aqui. Caso seja tomado dentro de uma perspectiva normativa, protocolar e hierárquica, "aconselhar" pode operar como uma ação de dessubjetivação e de disciplinarização (Foucault, 2005). Segundo nossa observação, a dificuldade de algumas psicólogas e de alguns psicólogos voluntários em lidar com marcadores sociais da diferença como identidade de gênero, por exemplo, pode gerar esse tipo de efeito, demandando uma análise crítica e uma revisão do aporte teórico que norteia o olhar e a prática de acolhimento.

\section{Pista 5: amparo e afeto numa prática engajada}

Jurandir Freire Costa (1998), em um texto que trata da palavra na democracia e na psicanálise, reúne, no próprio título, ainda que não estejamos trabalhando com esta última, dois termos caros ao que vivemos no momento: palavra, com sua potência no campo psi e no resto da vida, e democracia, esta que vemos tão ameaçada em nosso país no momento. O autor afirma que "o sujeito é pensado como um futuro imprevisível, e a imprevisibilidade, apesar de inquietante, deve ser investida como desejável. ..” (p. 109) para, na sequência, se colocar uma questão que tomamos como fundamental e a incorporamos a nossos pensamentos: "Como acolher a incerteza sem torná-la desamparo?” E sugere que na palavra possamos encontrar a possibilidade do "recomeço" (p. 110) - aspas do autor.

No acolhimento, tal como vimos construindo, cabe a incerteza e se promove a palavra. A palavra como possibilidade de criação, de se inventar, de construir caminhos, destituí-los, inventar outros. A palavra de quem precisa falar e a palavra de quem se dispõe a ouvir. E uma fala que, apesar de singular, não é solitária, tampouco isolada, característica que nos descreve fisicamente, neste momento.

A epidemia exige um cerceamento longo e uma troca da proximidade pela distância, na garantia do cuidado, que só experimentamos pontualmente em outros momentos da vida, quando se tem clareza de estar doente, clareza esta que o coronavírus não permite, como já dissemos antes. 
Além do medo de contrair a doença, a Covid-19 tem provocado sensação de insegurança em todos aspectos da vida: na saúde, na economia, no conhecer outras pessoas. A ideia de que "nada será como antes" já pode ser experimentada, como no caso de pessoas que se veem impedidas de enterrar seus familiares, e passam a ter de lançar mão de estratégias virtuais para prestar homenagens ao ente querido, como uma forma de ritualizar a morte e mitigar os sofrimentos decorrentes da perda (Ministério da Saúde, 2020c).

Portanto, vive-se nesse momento não apenas as incertezas, mas a imaterialidade dos processos e afetos que nos constituem no humano. O amparo se faz, então, como um movimento, uma teia tecida cotidianamente nos pequenos gestos e palavras. A tecnologia que nos permeia e o aparato que precisamos para estar no mundo reconfiguram nossos corpos. E a psicologia, mais do que se especializar tecnologicamente, necessita resgatar a artesania de suas práticas, justamente para poder recriá-las e não meramente acomodá-las. $\mathrm{E}$ isso nos exige um engajamento que suplanta os manuais e coloca em cena a importância de nos engajarmos na realidade que vivemos em nosso país.

O Brasil é marcado por desigualdades sociais imensas, com enormes bolsões de miséria e pobreza, educação formal inexistente ou precária e, como mais um traço deste panorama, grande parte da população não tem acesso ao que a tecnologia pode oferecer. Outros caminhos necessitam ser traçados para democratizar nossas práticas nesse contexto atravessado pelo inédito. Palavra e presença assumem novas formas e sentidos, como já apontado. A ideia de neutralidade, tão difundida historicamente em nossa área, pode tornar-se perigosa na medida em que a pandemia nos coloca diante de situações onde apostar na vida é, como afirma Haraway (1995), construir um conhecimento situado e engajado. Engajamento, afetividade e amparo são também instrumentos de intervenção, de suporte com uma ação reflexiva onde amparar e acolher o(a) outro(a) nos leva a buscar nossa própria rede de apoio, transformando nossa prática num movimento coletivizado, ainda que heterogêneo e múltiplo.

\section{Considerações finais: tracejando as pistas, desenhando o mapa}

A expressão "o novo normal” ganhou mundo. Ninguém sabe muito bem o que se quer dizer com isso, pois tal expressão pode ganhar pesos e sentidos bastante diversos, mas parece revelar dois aspectos importantes de um futuro incerto: a algo que não se conhece, o novo, se incute uma familiaridade para que seja suportável; a busca por algum controle ou conhecimento acerca de uma experiência absolutamente nova e imprevisível. Mesmo que, nos rastros de Canguilhem (1904/1995), tenhamos nossas restrições ao termo "normal", é compreensível que ela tenha tão rapidamente encontrado adesões.

O lema que tomou conta do país um tempo atrás, "ninguém solta a mão de ninguém", ainda reverbera. Só que agora, a mão segura um telefone, um iPad, um laptop. A expressão "você vem hoje?" ou "te vejo mais tarde" se atualizou no Zoom e em outros aplicativos de encontros virtuais, ou até mesmo nos bilhetes afetuosos que muitos estabelecimentos comerciais anexam às mercadorias nas entregas domiciliares. O encontro, então, não será no ponto de ônibus, no corredor da faculdade, no bar da cerveja gelada, no consultório da terapeuta. $\mathrm{O}$ acolhimento, de que tratamos neste artigo, precisa se intensificar. Seja na troca de mensagens pelo WhatsApp, em $e$-mails, nas variadas redes sociais que Chico Buarque (2017) elenca, sabiamente, em sua canção "Dueto”. Sim, o afeto vem das telas. 
A exaltação à importância de segurarmos a mão uns dos outros veio em resposta a momentos duros do país. $\mathrm{E}$ as cinco pistas aqui recolhidas não formam o território, mas nos desenham um mapa que pode nos nortear em nossos fazeres. E a própria escrita deste artigo, que se fez inteiramente a partir de uma comunicação virtual, nos trouxe descobertas, boas surpresas acerca da potência dos encontros que se fizeram a partir de uma mesma inquietação, um engajamento com o momento vivido e as afetações experimentadas por nós mulheres-cuidadoras-psicólogas- docentes-pesquisadoras aqui reunidas nesse vocábulo hifenizado na inspiração de Suely Rolnik (1989).

Acolher, afetar, praticar, afirmar a vida são verbos que nos ajudaram a compor essas pistas aqui dispostas e, como tal, nos convocam a agir. Como nos sugere Mol (2018), "As práticas viajam e uma pesquisadora pode tentar seguir-lhes aonde viajarem." (p. 298). Seguiremos, pois, nossa viagem com esse pequeno mapa inacabado, esboçado no fluxo dos acontecimentos, cientes de que há muito ainda por fazer. E que sigamos juntas, pois sim, juntas podemos ir mais longe, como preconizado na sabedoria popular.

\section{Referências}

Albuquerque, D. M. (2017). Nas profundezas rasas do corpo: semióticas a-significantes e processos de subjetivação e dessubjetivação dos marcadores sociais de gênero. In A. M. Veiga, C. R. Nichnig, C. S. Wolff, \& J. Zandona (Orgs.), Mundos de Mulheres no Brasil (pp. 73-86). Curitiba: Editora CRV.

Ayres, J. R. C. M. (2004). O cuidado, os modos de ser (do) humano e as práticas de saúde. Saúde e Sociedade, 13(3), 16-29. doi: 10.1590/S0104-12902004000300003

Bastos, C. (2002). Ciência, poder, ação: as respostas à Sida. Lisboa: Imprensa de Ciências Sociais (Universidade de Lisboa).

Bondía, J. L. (2002). Notas sobre a experiência e o saber de experiência. Revista Brasileira de Educação, 19(1), 20-28. doi: 10.1590/S1413-24782002000100003

Brehmer, L. C. F. \& Verdi, M. (2010). Acolhimento na atenção básica: reflexões éticas sobre a atenção à saúde dos usuários. Ciência E̊ Saúde Coletiva, 15(3), 3569-3578. doi: 10.1590/S1413$\underline{81232010000900032}$

Canguilhem, G. (1995). O normal e o patológico. Rio de Janeiro: Forense Universitária. (Original publicado em 1904)

Chico Buarque. (1980). Dueto [gravado por Chico Buarque de Holanda]. In Caravanas [CD]. Rio de Janeiro: Biscoito Fino.

Coimbra, C. \& Nascimento, M. L. (2008). Análise de implicações: desafiando nossas práticas de saber/poder. In A. R. R. Geisler, A. L. Abrahão, \& C. Coimbra (Orgs.), Subjetividade, violência e direitos humanos: produzindo novos dispositivos na formação em saúde (pp. 143-153). Niterói, RJ: EDUFF.

Costa, J. F. (1998). Não mais, não ainda: a palavra na democracia e na psicanálise. Revista USP, 1(37), 108-109. doi: 10.11606/issn.2316-9036.v0i37p108-119

Deleuze, G, \& Guattari, F. (1992) O que é a filosofia? Rio de Janeiro: Editora 34.

Deleuze, G. \& Guattari, F. (1996). Micropolítica e segmentaridade. In Mil Platôs: capitalismo e esquizofrenia (pp. 83-115). Rio de Janeiro: Ed. 34. 
Despret, V. (2004). Our Emotional Makeup: ethnopsychology and selfhood. New York: Other Press. Favret-Saada, J. (2005). Ser afetado. Cadernos de Campo, 13(13), 155-161. doi: 10.11606/ issn.2316-9133.v13i13p155-161

Foucault, M. (2005). Vigiar e punir: nascimento da prisão. Petrópolis, RJ: Vozes.

Haraway, D. (1995). Saberes localizados: a questão da ciência para o feminismo e o privilégio da perspectiva parcial. Cadernos Pagu, 5(1), 7-41.

Haraway, D. (2008). When Species Meet. Minneapolis, MN: University of Minnesota Press.

Kastrup, V. (2007). O funcionamento da atenção no trabalho do cartógrafo. Psicologia छ̊ Sociedade, 19(1), 15-22. doi: 10.1590/S0102-71822007000100003

Law, J. \& Mol, A. (1995). Notes on Materiality and Sociality. The Sociological Review, 1(43), 274-294.

Mbembe, A. (2018). Necropolítica (3a ed.). São Paulo: N-1 Edições.

Merhy, E. E. \& Franco, T. B. (2003). Por uma composição técnica do trabalho centrada nas tecnologias leves e no campo relacional. Saúde em Debate, 27(65), 345-353. Recuperado de https:// www.pucsp.br/prosaude/downloads/territorio/composicao tecnica do trabalho emerson merhy tulio franco.pdf

Ministério da Saúde. (2004). HumanizaSUS - Política Nacional de Humanização - A Humanização como Eixo Norteador das Práticas de Atenção e Gestão em Todas as Instâncias do SUS. Brasília, DF: Autor. Recuperado de http://bvsms.saude.gov.br/bvs/publicacoes/humanizasus 2004.pdf

Ministério da Saúde. (2010). Acolhimento nas práticas de produção de saúde. Brasília, DF: Autor. Recuperado de https://bvsms.saude.gov.br/bvs/publicacoes/acolhimento praticas producao saude.pdf

Ministério da Saúde. (2020a). Saúde mental e atenção psicossocial na Covid-19 - A Quarentena na Covid-19: orientações e estratégias de cuidado. Brasília, DF: Autor. Recuperado de https:// www.fiocruzbrasilia.fiocruz.br/wp-content/uploads/2020/04/Sa\%c3\%bade-Mental-e-Aten \%c 3\%a 7\%c3\%a3o-Psicossocial-na-Pandemia-Covid-19-A-quarentena-na-Covid-19-orienta\%c3\%a7\%c3\%b5es-e-estrat\%c3\%a9gias-de-cuidado.pdf

Ministério da Saúde. (2020b). Saúde mental e atenção psicossocial na Covid-19: orientações às/aos psicólogas/os hospitalares. Brasília, DF: Autor. Recuperado de https://www.fiocruzbrasilia.fiocruz.br/wp-content/uploads/2020/04/cartilha psicologos hospitalares.pdf

Ministério da Saúde. (2020c). Saúde mental e atenção psicossocial na Covid-19: processo de luto na Covid-19. Fiocruz Brasília, DF: Autor. Recuperado de http://renastonline.ensp.fiocruz.br/ sites/default/files/arquivos/recursos/saude-mental-e-atencao-psicossocial-na-pandemia-covid-19-processo-de-luto-no-contexto-da-covid-19.pdf

Ministério da Saúde. (2020d). Saúde mental e atenção psicossocial na Covid-19: recomendações aos psicólogos para o atendimento online. Brasília, DF: Autor. Recuperado de https://www. fiocruzbrasilia.fiocruz.br/wp-content/uploads/2020/04/Sa\%c3\%bade-e-Mental-e-Aten\%c3\%a7\%c3\%a3o-Psicossocial-na-Pandemia-Covid-19-recomenda\%c3\%a7\%c3\%b5es-aos-psic\%c3\%b3logos-para-o-atendimento-online-1.pdf

Ministério da Saúde. (2020e). Saúde mentale atenção psicossocial na Covid-19: recomendações gerais. Brasília, DF: Autor. Recuperado de https://www.fiocruzbrasilia.fiocruz.br/wp-content/uploads/2020/04/Sa\%c3\%bade-Mental-e-Aten\%c3\%a7\%c3\%a3o-Psicossocial-na-Pandemia-Covid-19-recomenda\%c3\%a7\%c3\%b5es-gerais.pdf 
Ministério da Saúde. (2020f). Saúde mental e atenção psicossocial na Covid-19: recomendação para gestores. Brasília, DF: Ministério da Saúde. Recuperado de https://www.fiocruzbrasilia.fiocruz. br/wp-content/uploads/2020/04/Sa\%c3\%bade-Mental-e-Aten\%c3\%a7\%c3\%a3o-Psicossocial-na-Pandemia-Covid-19-recomenda\%c3\%a7\%c3\%b5es-para-gestores.pdf

Ministério da Saúde. (2020g). Saúde mental e atenção psicossocial na Covid-19: violência doméstica efamiliar na Covid-19. Brasília, DF: Autor. Recuperado de https://www.fiocruzbrasilia.fiocruz. br/wp-content/uploads/2020/04/Sa\%c3\%bade-Mental-e-Aten\%c3\%a7\%c3\%a3o-Psicossocial-na-Pandemia-Covid-19-viol\%c3\%aancia-dom\%c3\%a9stica-e-familiar-na-Covid-19.pdf

Mol, A. (2007). Política Ontológica. Algumas ideias e várias perguntas. In J. A. Nunes \& R. Roque (Eds.), Objectos Impuros: Experiências em Estudos sobre a Ciência (pp. 1-24). Porto, PT: Edições Afrontamento.

Mol, A. (2008). The Logic of Care: Health and the Problem of Patient Choice. London: Routledge.

Mol, A. (2018). Corpos múltiplos, ontologias políticas e a lógica do cuidado: uma entrevista com Annemarie Mol. In Entrevista concedida a D. Martin, M. J. Spink, \& P. P. G. Pereira. Interface - Comunicação, Saúde, Educação, 22(64), 295-305. doi: 10.1590/1807-57622017.0171

Passos, E., Kastrup, V., \& Escóssia, L. (2009). Apresentação. In Pistas do método da cartografia: pesquisa-intervenção e produção de subjetividade (pp. 07-16). Porto Alegre: Sulina.

Pelisoli, C., Sacco, A. M., Barbosa, E. T., Pereira, C. O., \& Cecconello, A. M. (2014). Acolhimento em saúde: uma revisão sistemática em periódicos brasileiros. Estudos de Psicologia, $31(2)$, 225-235. doi: 10.1590/0103-166X2014000200008

Pozzana, L. \& Kastrup, V. (2009). Cartografar é acompanhar processos. In E. Passos, V. Kastrup, \& L. Escóssia (Orgs.), Pistas do método da cartografia: pesquisa-intervenção e produção de subjetividade (pp. 52-75). Porto Alegre, RS: Sulina.

Quadros, L. C. T. \& Moraes, M. (2016). Polifonia de uma experiência no ESOCITE. Pesquisas e Práticas Psicossociais, 11(1), 4-7. Recuperado de http://pepsic.bvsalud.org/pdf/ppp/v11n1/o1.pdf

Rolnik, S. (1989). Cartografia sentimental: transformações contemporâneas do desejo. São Paulo: Estação Liberdade.

Santos, B. S. (2020, 02 de julho). Boaventura: a universidade pós-pandêmica. OutrasPalavras. Recuperado de https://outraspalavras.net/alemdamercadoria/boaventura-a-universidade-pos-pandemica/

Speroni, A. V. \& Menezes, R. A. (2014). Os sentidos do Acolhimento: um estudo sobre o acesso à atenção básica em saúde no Rio de Janeiro. Cadernos Saúde Coletiva, 22(4), 380-385. doi: $10.1590 / 1414-462 \times 201400040011$

Stengers, I. (1989). A Ciência no Feminino. Revista 34 Letras, 5(6), 427-431. 


\section{LAURA CRISTINA DE TOLEDO QUADROS}

http://orcid.org/0000-0002-3546-4935

Professora adjunta do Instituto de Psicologia da Universidade do Estado do Rio de Janeiro. Doutora em Psicologia Social pelo Programa de Pósgraduação em Psicologia Social da Universidade do Estado do Rio de Janeiro (UERJ).

Endereço: Rua São Francisco Xavier, 524, Bloco B, $10^{\circ}$ andar, sala 10.019. Maracanã - Rio de Janeiro, RJ - Brasil. CEP: 20550013

E-mail: lauractq@gmail.com

\section{CLAUDIA CARNEIRO DA CUNHA}

https://orcid.org/0000-0002-2338-6386

Professora adjunta do Instituto de Psicologia da Universidade do Estado do Rio de Janeiro (UERJ). Doutora em Antropologia Social pela Universidade Federal do Rio de Janeiro (MN/UFRJ).

E-mail: cunha.claudia@gmail.com

\section{ANNA PAULA UZIEL \\ http://orcid.org/0000-0001-7807-3910}

Professora associada do Instituto de Psicologia da Universidade do Estado do Rio de Janeiro. Doutora em Ciências Sociais pela Universidade Estadual de Campinas, SP.

E-mail: uzielap@gmail.com

\begin{tabular}{|l|l|}
\hline \multirow{2}{*}{ Histórico } & $\begin{array}{l}\text { Submissão: 30/06/2020 } \\
\text { Revisão: 24/07/2020 } \\
\text { Aceite: 27/07/2020 }\end{array}$ \\
\hline $\begin{array}{l}\text { Concepção: L.C.T.Q., C.C.C., A.P.U. } \\
\text { dos autores } \\
\text { Elaboração do manuscrito: L.C.T.Q., C.C.C., A.P.U. } \\
\text { Revisões críticas de conteúdo intelectual importante: } \\
\text { L.C.T.Q., C.C.C., A.P.U. } \\
\text { Aprovação final do manuscrito: L.C.T.Q., C.C.C., A.P.U. }\end{array}$ \\
\hline $\begin{array}{l}\text { Consentimento } \\
\text { de uso de imagem }\end{array}$ & \begin{tabular}{l} 
Não se aplica. \\
\hline $\begin{array}{l}\text { Aprovação, ética } \\
\text { e consentimento }\end{array}$
\end{tabular} \\
\hline Financiamento & Não houve financiamento. \\
\hline
\end{tabular}

